\title{
Early Intervention for Psychosis in Hong Kong - The EASY Programme
}

Jennifer Y.M. Tang, ${ }^{1}$ Gloria H.Y. Wong, ${ }^{1}$ Christy L.M. Hui, ${ }^{1}$ May M.L. Lam,${ }^{1}$ Cindy P.Y. Chiu, ${ }^{1}$ Sherry

K.W. Chan, ${ }^{1}$ Dicky W.S. Chung, ${ }^{2}$ Steve Tso, ${ }^{3}$ Kathy P.M. Chan, ${ }^{4}$ K.C. Yip, ${ }^{5}$ S.F. Hung ${ }^{4}$ and Eric Y.H.

Chen $^{1}$

1 Department of Psychiatry, The University of Hong Kong, Hong Kong.

2 Department of Psychiatry, Tai Po Hospital, Hong Kong.

3 Department of Psychiatry, Castle Peak Hospital, Hong Kong.

4 Department of Psychiatry, Kwai Chung Hospital, Hong Kong.

5 Department of Psychiatry, Kowloon Hospital, Hong Kong.

\section{Corresponding Author}

Eric YH Chen, Department of Psychiatry, The University of Hong Kong, Queen Mary Hospital,

Pokfulam Road, Hong Kong.

Email: eyhchen@hku.hk

Tel: (852) 22554488

Fax: (852) 22551345 


\section{Abstract}

Aim: This article aims to describe the Hong Kong experience in developing and implementing an early psychosis programme.

Methods: In 2001, the Early Assessment Service for Young People with Psychosis programme (EASY) was launched in Hong Kong, providing both educational and service components. Public education includes promotion of timely help-seeking, accessible channels to service, and knowledge of psychosis. The 2-year phase-specific intervention includes intensive medical follow-up and individualized psychosocial intervention. The programme has adopted the case-management approach, in which case managers provide protocol-based psychosocial intervention. The programme collaborates with non-governmental organizations and community networks in the provision of rehabilitation service.

Results: An average of over 600 young patients enter the programme for intensive treatment each year. Based on preliminary data from a three-year outcome study, patients in the programme have remarkable reductions in hospital stay accompanied by improvements in vocational functioning.

Conclusions: The results suggested that the programme improved patients' outcome. Additional costs such as extra medical staff and medications may be offset by the shortened 
hospital stay. Further directions in early intervention are also discussed.

\section{Key words}

Adolescent

Mental Health Services

Early Diagnosis

Health Service Accessibility

Psychotic Disorders

\section{INTRODUCTION}

Hong Kong has a population of around seven million. In 2006, the health expenditure

constituted $5.2 \%$ of the gross domestic product, ${ }^{1}$ which was lower than many high income

countries such as the United Kingdom (8.2\%), the United States (15.3\%), and Japan (8.1\%), but

higher than Singapore (3.3\%). ${ }^{2}$ Psychiatric healthcare in Hong Kong is mainly provided by the

public system, with supplementation by some private services. In March 2009, the healthcare

workers in the public psychiatric units included 288 clinicians, 1,880 psychiatric nurses

(including 133 community nurses), and 197 medical social workers serving a total of 
approximately 150,000 psychiatric patients. ${ }^{3}$

To access public psychiatric service, a referral letter issued by a general physician is required. Waiting time from referral to service is sometimes weeks, but usually months.

Additional obstacles to care stem from stigma and inadequate knowledge. A local case-vignette survey reported that the public awareness of psychotic symptoms was low.4 The majority of respondents opined that a person with psychotic symptoms may be improved solely by taking a break. Only 3\% reported that medication would be helpful. The service barrier and social obstacles often keep the patients-in-need from timely interventions. As a result, patients often first present to service through Accident Emergency Departments (AEDs), and are subsequently admitted as in-patients. General public psychiatric out-patient clinics for stabilized patients are characterized by high service volume, brief consultation time (5-6 minutes per consultation), 5 and little resources for community support. For instance, only $6 \%$ of the discharged in-patients were followed up by a community support service. ${ }^{6}$

The development of early intervention for psychosis is underpinned by the evidence that delayed treatment is associated with poorer outcome. Recent meta-analyses report that patients with longer duration of untreated psychosis (DUP) have worse short-term outcomes in terms of treatment response, positive symptoms, negative symptoms, and functioning.7,8 Early 
detection aims to reduce treatment delay, in the hope of improving prognosis and reducing illness severity. ${ }^{9}$ As there is evidence that early outcome is predictive of long-term disease course, ${ }^{10}$ effective secondary prevention such as phase-specific intervention may optimize treatment response and reduce disease burden.

In view of budgetary constraints in implementing early intervention programmes, a population-based programme is suggested to be an optimal funding model.11 In 2001, a population-based early intervention programme, the Early Assessment Service for Young People with Psychosis (EASY), was launched within the Hong Kong public healthcare system.

\section{THE PROGRAMME STRUCTURE}

The three main components of the programme are (i) raising public awareness; (ii) creating an easily accessible channel for service; and (iii) providing phase-specific intervention. The programme is led by a steering committee, which consists of experienced clinicians from the programme and major psychiatric units, and representatives from nursing and public affairs divisions of the Hospital Authority. The steering committee decides on the service directions, while individual intervention teams have flexibility to decide on the operational details.

The programme has five intervention teams serving independent catchment areas. Each team consists of two psychiatrists, three case managers (psychiatric nurses or medical social 
workers), and one clinical psychologist (shared between four sites). Each case manager

manages approximately 80 patients at any one time. The teams also partner with their local non-governmental organizations (NGOs) and community networks for provision of community services. To enhance professional development, the programme arranges monthly training sessions for programme staff.

Resource limitations led to allocation preference for younger patients for whom disease burden is higher and outcome poorer.12,13 Therefore, the intervention targets young people aged 15 to 25 years with psychotic symptoms. The age range was set based on incidence estimates. Details of the intake and exclusion criteria are described in Table 1. Identified cases receive two years of phase-specific intervention.

$$
\text { [Insert table } 1 \text { here] }
$$

\section{Public awareness programme}

The public awareness campaign is coordinated by a workgroup composed of experienced clinicians and experts from the public affairs division of Hospital Authority. During the launch of EASY, the public education programmes aimed to deliver three core services: (i) encourage timely help-seeking; (ii) promote accessible channels for service; and (iii) enhance public knowledge of psychotic symptoms. The messages were carefully packaged in order to be 
communicated effectively. Mediums to channel the messages included TV, advertisements, radio interviews, press releases, websites, exhibitions, public talks, road shows, posters, and leaflets.

To facilitate a proper understanding and acceptance of psychosis, an EASY workgroup was formed to develop a more accurate and informative Chinese term for "psychosis," which was previously inappropriately translated to mean "severe mental illness". The new translation “si-jue shi-tiao” (思覺失調) literally means dysregulation (失調shi-tiao) in thinking (思si) and perception (覺jue). ${ }^{14,15}$ The public has adopted the new term in an increasingly positive manner. Detailed description and rationale for the naming process are discussed separately. ${ }^{16}$

\section{Easily accessible channels}

The programme has lowered the entry barrier to service with an open and direct referral system. The service accepts walk-ins and a broad range of referrals from the community and within the healthcare system. The former includes referrals through hotline, e-mail, NGOs, and school social workers. The latter includes out-patient departments, consultation and liaison teams, in-patient departments, and AEDs. A widely publicized hotline and online referral system enable direct access to the programme case managers.

Stage 1 initial assessment is a hotline-based screening interview conducted by case 
managers. They are primarily psychiatric nurses experienced in engagement and screening of potential cases. They gather information from clients, informants or both. Those who appear to meet the criteria for psychosis are referred to an EASY clinician for Stage 2 clinical assessment within a week. Assessments are arranged in a non-stigmatizing setting such as in a general hospital, NGO, or the patient's home, if necessary. Identified cases will be given two years of intensive care. Although individuals clinically judged to have high risk of developing psychosis are not the target recipients for the programme, they are monitored in out-patient clinics regularly and are given medications, psychosocial treatment, or both on need basis.

Phase-specific intervention will be given only if conversion takes place. Ineligible cases with a need for medical attention are diverted to appropriate services.

\section{Phase-specific intervention}

Phase-specific intervention is characterized by case management, intensive medical follow-up, and enhanced rehabilitation services. Case managers provide psychosocial intervention in alignment with the Psychological Intervention Programmes in Early Psychosis (PIPE), ${ }^{17}$ a programme-specific protocol with reference to the International Clinical Practice Guidelines for Early Psychosis. ${ }^{18}$ The PIPE has three main components: (i) enhancing psychological adjustment to early psychosis; (ii) intervention for secondary morbidity; and (iii) cognitive 
behavioural therapy for drug-resistant psychotic symptoms. The first component is designed

for most patients while the latter two are specifically for patients in need.

Each patient is assigned a case manager who formulates an individualized care plan

according to the patient's stage of illness and needs. Intervention approaches can be organized

on a group or individual basis.

Initial management

In the early stage of illness, patients and their families are often highly distressed and

overwhelmed by the illness. Case managers aim to establish early therapeutic alliances with

patients and their families. Collaboration with family members is a key process as Hong Kong

adolescents usually live with their parents. Parent roles may include providing information,

monitoring the patient's adherence in treatment, detecting early signs of relapse and mood

symptoms, and facilitating the patient's psychosocial adaptation. To establish effective

communication with patients and their families, the engagement process starts early and lasts

throughout the treatment period.

Second-generation antipsychotics may be the first-line treatment for active psychotic

symptoms or are used when low-dose first-generation antipsychotics are inefficacious or

intolerable, so as to minimize extrapyramidal side effects. Concomitant medications are 
prescribed for mood and anxiety symptoms. In-patient treatment is considered in the cases of acute psychosis or risk averse and aggressive behaviour.

Psychosocial intervention aims to help patients develop a more positive attitude to the illness in order to facilitate recovery. Through psychoeducation, such interventions assist patients in building an explanatory model, often the vulnerability-stress model, ${ }^{19}$ to understand the development of their illness. Psychoeducation also covers knowledge of topics such as aetiology, symptomatology, medications, and side effects. Thus, case managers readily discuss the common myths and misconceptions about psychosis with patients and their families. Individual or family intervention is also provided in response to emotional maladaptation (e.g., distress, high expressed emotions, or guilt) and coping difficulty. With intensive medical follow-up and psychosocial support, patients are mostly managed under out-patient care and community facilities.

\section{Management during recovery period}

Upon stabilization of illness, the programme provides continual intensive care. The management is broadened to the promotion of recovery and relapse prevention. To reduce the risk of relapse, international clinical guidelines suggest that maintenance antipsychotic treatment should be at least one year, possibly longer.18,20,21 While emphasising treatment 
adherence, clinicians also take flexible measures to relieve a patient's burden of treatment. In many cases relapse can be detected early and managed under out-patient care. Other assertive measures practiced by case managers include active tracing of disengaged patients, regular phone contact, and home visits.

Despite the role of maintenance medication, local data suggest that many patients view the cessation of medication as a necessary condition of recovery. ${ }^{22}$ Case managers encourage patients to evaluate their recovery progress with multi-dimensional perspectives such as symptom control, independent living, employment, and social network. Intervention aiming for life restructuring guides patients to develop goals and resources, maintain social networks, and establish routines, ideally employment. Stress management involves both patients and their families in understanding and predicting stress-inducing situations, and developing coping strategies. Psychoeducation in this period extends to topics of maintenance treatment, early relapse sign detection, and strategies in response to relapse and crisis. These measures aim to progressively guide patients to visualize their path of recovery and readjust their expectations, while remaining hopeful.

Specific interventions are also introduced. For instance, cognitive behavioural therapy targets patients with persistent psychotic symptoms, functional impairment, and 
secondary morbidity (e.g. depression and social anxiety). Occupational therapy is arranged

when necessary. NGOs and vocational training centres work closely with the programme. They organize rehabilitation programmes and provide facilities for enhancing patients' re-integration into the community. These include half-way houses, sheltered workshop, day-care facilities, etc.

The phase-specific intervention lasts for two years. The pace and actual content of intervention is tailored according to individuals' needs. Individual care plans are reviewed in regular multidisciplinary meetings. Patients enter a transitional step-down clinic in year three (preserved medical follow-up, but no input from case managers) and are transferred to generic psychiatric care thereafter.

\section{PROGRAMME OUTCOME}

An internal review was done to evaluate the utilization of the programme (Lam 2008, personal communication). The service received a mean of 1,267 referrals each year. Around 1,026

$(80.9 \%)$ of the referred cases received psychiatric assessment. Among the assessed cases, around 613 (59.7\%) met the intake criteria and received intensive treatment. Among the remaining 413 cases, around 223 (53.9\%) were assessed as "high risk" cases and were monitored regularly by the programme. Median response time between referral and diagnostic 
assessment was five days.

In 2006, an extensive outcome evaluation was carried out in the form of a cohort study 23 comparing the three-year outcome of 700 patients in the programme with 700 matched historical controls in standard care. Historical controls were used as the territory-wide nature of the programme precluded concurrent control groups. The mean DUP in the early intervention group was comparable to that in the historical control group $(\mathrm{P}=0.72)$. EASY patients had significant reduction in hospital stay $(\mathrm{P}<0.001)$ and improvement in occupational functioning $(\mathrm{P}<0.001)$. As the major findings were independent of DUP and remained robust after adjusted for the use of second-generation antipsychotics, favourable outcomes were more attributable to the phase-specific intervention. Although the study was not intended for a direct cost analysis, the preliminary data showed that additional cost (staff and medications) might be offset by reduction in hospital stay; this reduction could be, at least in part, product of early intervention programmes. Detailed description of the programme effectiveness is reported separately. ${ }^{24}$

The mental health system in Hong Kong is characterized by its heavy reliance on public service and low resources. The study demonstrated that an early intervention was effective in improving short-term outcome even with a relatively high case manager-to-patient ratio 
(1:80). The limited resources made the development of a specialized service particularly challenging, a situation which was also encountered by the early intervention programme in Singapore, namely the Early Psychosis Intervention Programme (EPIP).25 Each case manager of EPIP manages approximately 37 patients at any one time (an average of 202 new cases per year, who are managed by a total of 11 case managers for 2 years), ${ }^{26}$ a caseload lower than the EASY programme but still higher than other Western programmes. ${ }^{27}$ Like the programme in the present outcome study, the EPIP programme was effective in reducing excessive use of medications, improving consultation attendances, improving vocational outcome, and reducing DUP.25 It will be worth examining whether outcome of the EASY programme, particularly DUP and relapse that the programme had no effect on, will be further improved by lowering the keywoker-to-patient ratio.

Although the intensity of the EASY programme was not comparable to that of the programmes in the Western populations, the small intervention team might be balanced by strong familial support. Over $90 \%$ of the people below age 25 in Hong Kong were living with their parents. ${ }^{28} \mathrm{~A}$ previous local study showed that previous family experience of psychiatric illness predicted a shorter DUP. ${ }^{29}$ However, this study was unable to address whether such environmental factors increased the effectiveness of the smaller intervention team in 
improving outcome.

\section{CONCLUSIONS}

Preliminary data suggest that early intervention in Hong Kong has been effective in improving

the outcome of early psychosis. Components contributing to the success might include the

specialized team with a case-management approach and phase-specific individualized care.

However, a randomized controlled study reports that not all of the positive results of two-year

specialized service, such as symptomatology and global functioning, are sustainable through

the fifth year. ${ }^{30}$ There is a need for more randomized controlled trials to address the question of

the optimal intervention period. In 2009, eight years after the early intervention initiative in

Hong Kong discussed in the present research, a five-year early psychosis project for adult

patients (aged above 25) was launched. The project serves education, research, and service

purposes. A total of 450 participants in the research component will be randomized to three

groups: two-year case management, four-year case management and controls with basic care

only ( $\mathrm{n}=150$ for each group). The results of the study will be important for addressing the

optimal critical intervention period, as well as economic implications implied by the present

study. 
Table 1. Intake and exclusion criteria for EASY service†

Intake criteria:

- Presence of psychotic symptoms

- $\quad$ Age between 15 to 25 years

Exclusion criteria:

- Already receiving treatment for psychosis

- Significant medical illnesses affecting the central nervous system (e.g., epilepsy, serious head injury with loss of consciousness)

- Moderate to severe intelligence deficiency

- Psychotic episode is substance induced

†Excluded clients are directed to other services where appropriate (e.g., substance abuse clinic). Individuals with high risk of developing psychosis are monitored in outpatient clinics regularly, and are given medications, psychosocial intervention, or both on need basis.

Phase-specific intervention will be given only if conversion takes place. 


\section{REFERENCES}

1. Food and Health Bureau, the Government of the Hong Kong Special Administrative

Region. Hong Kong's Domestic Health Accounts - Estimate of Domestic Health

Expenditure, 1989/90 - 2005/06. [updated 2009 Sep 9; cited 2010 Apr 7]. Available

from URL: http://www.fhb.gov.hk/statistics/en/dha.htm.

2. World Health Organization. Health expenditure. World Health Statistics 2009. [cited 2010

Apr 7]: Available from URL: http://www.who.int/whosis/whostat/2009/en/index.html.

3. Legislative Council of the Hong Kong Special Administrative Region. Administration's

paper on community support services for ex-mentally ill persons. 2009. [updated 2009

Jun 8; cited 2009 Oct 13]. Available from URL:

http://www.legco.gov.hk/yr08-09/english/panels/ws/papers/ws0608cb2-1711-3-e.pd

f.

4. Lam LC, Chan CK, Chen EY. Insight and general public attitude on psychotic experiences in Hong Kong. Int J Soc Psychiatry 1996; 42 (1): 10-7.

5. Hui CLM, Wong GHY, Lam CYK, Chow PPL, Chen EYH. Patient-clinician communication and needs identification for outpatients with schizophrenia in Hong Kong: Role of the 2-COM Instrument. Hong Kong J Psychiatry 2008; 18: 69-75. 
6. Legislative Council of the Hong Kong Special Administrative Region. Paper on community support services for ex-mentally ill persons (background brief). 2009. [updated 2009 Sep 24; cited 2009 Oct 13]. Available from URL: http://www.legco.gov.hk/yr08-09/english/panels/ws/papers/hsws0930cb2-2525-2-e.p df.

7. Marshall M, Lewis S, Lockwood A, Drake R, Jones P, Croudace T. Association between duration of untreated psychosis and outcome in cohorts of first-episode patients: a systematic review. Arch Gen Psychiatry 2005; 62 (9): 975-83.

8. Perkins DO, Gu H, Boteva K, Lieberman JA. Relationship between duration of untreated psychosis and outcome in first-episode schizophrenia: a critical review and meta-analysis. Am J Psychiatry 2005; 162 (10): 1785-804.

9. Larsen TK, McGlashan TH, Johannessen JO, et al. Shortened duration of untreated first episode of psychosis: changes in patient characteristics at treatment. Am J Psychiatry 2001; 158 (11): 1917-9.

10. Harrison G, Hopper K, Craig T, et al. Recovery from psychotic illness: a 15- and 25-year international follow-up study. Br J Psychiatry 2001; 178:506-17.

11. Chen EYH, Wong GHY, Lam MML, Chiu CPY, Hui CLM. Real-world implementation of early 
intervention in psychosis: resources, funding models and evidence-based practice. World Psychiatry 2008; 7 (3): 7-8.

12. Rabinowitz J, Levine SZ, Hafner H. A population based elaboration of the role of age of onset on the course of schizophrenia. Schizophr Res 2006; 88 (1-3): 96-101.

13. Rossler W, Salize HJ, van Os J, Riecher-Rossler A. Size of burden of schizophrenia and psychotic disorders. Eur Neuropsychopharmacol 2005; 15(4): 399-409.

14. Wong GHY, Hui CLM, Chiu CPY, et al. Early detection and intervention of psychosis in Hong Kong: experience of a population-based intervention programme. Clin Neuropsychiatry 2008; 5 (6): 286-9.

15. Chen EYH. Developing an early intervention service in Hong Kong. In: Ehmann T, MacEwan GW, Honer WG, editors. Best Care in Early Psychosis Intervention: Global Perspectives. London ; New York: Taylor \& Francis; 2004.

16. Chiu CPY, Lam MML, Chan SKW, et al. Naming psychosis - The Hong Kong experience. Manuscript in preparation.

17. Wong C, Chong H. Psychological intervention programmes for people with early psychosis (PIPE) Manual. Hong Kong: Early Assessment Service for Young People with Psychosis; 2002. 
18. International Early Psychosis Association Writing Group. International clinical practice guidelines for early psychosis. Br J Psychiatry 2005; 187 (Suppl. 48): s120-4.

19. Strauss JS, Carpenter WT. Schizophrenia. New York: Plenum Press; 1981.

20. American Psychiatric Association. Practice guideline for the treatment of patients with schizophrenia. Am J Psychiatry 1997; 154 (Suppl. 4): 1-63.

21. Lehman AF, Lieberman JA, Dixon LB, et al. Practice guideline for the treatment of patients with schizophrenia, second edition. Am J Psychiatry 2004; 161 (Suppl. 2): 1-56.

22. Ng RMK, Pearson V, Lam M, Law CW, Chiu CPY, Chen EYH. What does recovery from schizophrenia mean? Perceptions of long-term patients. Int J Soc Psychiatry 2008; 54 (2): 118-30.

23. Chen EYH, Tang JYM, Hui CLM, et al. Outcome of an early intervention programme for psychosis: A controlled study. Health Research Symposium; Hong Kong 2008.

24. Chen EYH, Tang JYM, Hui CLM, et al. Three-year outcome of phase-specific early intervention for first-episode psychosis: a cohort study in Hong Kong. Manuscript in preparation.

25. Chong SA, Verma S, Mythily S, Poon Ly, McGorry PD. The early psychosis intervention programme in Singapore: A balanced scorecard approach to quality care. J Ment Health 
2008; 17 (1):79-91.

26. The Early Psychosis Intervention Programme. [cited 2010 May 13]. Available from URL: http://www.epip.org.sg.

27. Jorgensen P, Nordentoft M, Abel MB, Gouliaev G, Jeppesen P, Kassow P. Early detection and assertive community treatment of young psychotics: the Opus Study Rationale and design of the trial. Soc Psychiatry Psychiatr Epidemiol 2000; 35 (7):283-7.

28. Census and Statistics Department, the Government of the Hong Kong Special Administrative Region. Women and Men in Hong Kong - Key Statistics. 2009. [updated 2009 Jul 30; cited 2010 Apr 19]. Available from URL:

http://www.censtatd.gov.hk/products and services/products/publications/statistical r eport/social data/index cd B1130303 dt detail.jsp.

29. Chen EY, Dunn EL, Miao MY, Yeung WS, Wong CK, Chan WF, et al. The impact of family experience on the duration of untreated psychosis (DUP) in Hong Kong. Soc Psychiatry Psychiatr Epidemiol 2005; 40 (5):350-6.

30. Bertelsen M, Jeppesen P, Petersen L, et al. Five-year follow-up of a randomized multicenter trial of intensive early intervention vs standard treatment for patients with a first episode of psychotic illness: the OPUS trial. Arch Gen Psychiatry 2008; 65 (7): 762-71. 